\title{
The psychological aspects of social integration of a person
}

\author{
Irina Akhmetshina ${ }^{1, *}$, Natalia Filina $^{2}$, Elena Petrova $^{1}$, and Irina Sokolovskaya $^{3}$ \\ ${ }^{1}$ State University of Humanities and Technology, 142600, Zelenaya street, 22, Moscow Region, \\ Orekhovo-Zuevo, Russia \\ ${ }^{2}$ Russian State Social University, 129226, Wilhelm Pieck street, 4, build.1, Moscow, Russia \\ ${ }^{3}$ State University of Management, 109542, Ryazan Ave., 99, Moscow, Russia
}

\begin{abstract}
The socio-economic transformations identified the necessity to improve the socio-pedagogical work in the penitentiary system. This is important for the humanization of the rehabilitation process through the educational activities' organization, the search for effective forms, methods and means of influencing the consciousness and behavior of convicts. The most important values for convicts are those that will ensure their individual existence, and the values that reflect the social essence are relegated to the background in conditions of social isolation. A temporarily socially isolated person, who disconnected from the usual environment, reduces adaptive capabilities. It determines to analyze the influence of educational technologies on the process of socio-pedagogical work in conditions of the necessity of decreasing the recidivism. To stimulate appropriate social integration, which is in demand by the society and aimed at mastering new social roles and necessary skills of constructive social behavior after release. Method of theoretical analysis and systematization of scientific ideas; theoretical analysis of the resources; the study and generalization of the experience of social educators-innovators; observations, conversations, were used. The conclusions create prerequisites for updating the existing technologies of socio-pedagogical work in penitentiary institutions.
\end{abstract}

\section{Introduction}

The residence in the correctional facilities is a difficult life situation for a person. We need to make comfortable organizational psychoeducational and social conditions for the correction and social integration during the period of serving the penalty. Most of the convicts do not seek correction and, and when they release, commit a new crime. Therefore, there is a necessity to study how to use educational technologies in the work of a social teacher to change the legal intolerance of convicts for the better. The penitentiary social assistance is important because the convicts do not have an opportunity to contact the specialists for help due to restrictions on their rights and freedoms. In this regard, the essence of sociopedagogical technologies is precisely to ensure that the rights and freedoms of those people

\footnotetext{
${ }^{*}$ Corresponding author: irenaveger@gmail.com
} 
who are serving the sentences are respected. In our opinion, it is important to identify the essence of the process of correcting intolerance in order to form socially significant personality traits and socially approved behavior experience in convicts, in determining the significance of technologies of socio-pedagogical work in penitentiary institutions. The activity of the social teacher should include the systematic solution of a whole complex of socio-pedagogical tasks aimed at the implementation of such functions as educational, developmental, training and self-correction. The problem of studying the personality of the convicts is found in works of U.A. Voronin [1], E.Z. Giniyatullin [2], D.I. Erezhipaliev [3], A.A. Zajnetdinova, A.A. Rezyapov [4], N.M. Romanova [5], J. Braithwaite [6], G. Drawve, J.T. Walker \& M. Felson [7], M.J.J. Kunst, B.W.C. Zwirs [8], Y. Loader, R. Sparks [9], R. Surette [10] etc. The basic positions in terms of understanding the organization of a holistic socio-pedagogical process in the penitentiary system are reflected in the works ofK.N. Kalashnikov [11], R. Adelman, L.Williams Reid, G. Markle, S. Weiss \& J. Charles [12], T.R. Kochel [13], L. Maria, D. Canter, D. Youngs, J. Synnott [14] etc. The pedagogical foundations of the correction of convicts are considered in the works of I.A.Ahmetshina [15], N.V. Ol'hovik [16], O.A. Ryzhova [17], H. Hofer [18] etc. The theoretical analysis of the domestic and foreign scientific literature showed that socio-pedagogical conception of personality's socialization is more productive today, because it can integrate the educational forces of all the participants in correctional activities for the purpose of social integration of convicts. All of this makes it necessary to use adequate pedagogical correctional tools in the conditions of the modern reality of the penitentiary system.

\section{Materials and methods}

We made a skilled-experimental work based on Federal State Institution "Pre-trial Detention Center No. 11" of the Department of the Federal Service for Correction of Punishment of Russia in the Moscow Region in the city of Noginsk. The sample consisted of 7 people, aged 23-25 years, who are the first-time convicts. We used the methods of theoretical analysis and systematization of scientific ideas; study and analysis of regulatory documents; the theoretical analysis of philosophical, socio-pedagogical and psychological sources; the study and generalization of the experience of social educators-innovators; observation, conversation, personal questionnaire EPI (G. Aizenck), questionnaire of socio-psychological adaptation (K. Rogers and R. Diamond), the test "Strategy of behavior in a conflict situation" (K. Thomas).

\section{Results}

The penitentiary system was made for the rehabilitation of offenders and prevent them from committing new crimes, law enforcement and rule of law in their treatment of the corrections, security, labour, their general and professional education, ensuring health government. To implement a purposeful socio-pedagogical, rehabilitation process of re-education, "treatment" of socially neglected prisoners, it is necessary that correctional labor institutions become a kind of social clinics. That is why, it is necessary to have the social workers, who orient on the moral and humanistic principles in relation to convicts. The essence of the sociopedagogical work in penitentiary institutions is to preserve the norms, values and traditions of humanistic education. This approach is especially important now, when it is considered that convicts cannot be clients of social work, since they are serving their sentences and, as a result, they are not full members of society. In fact, the society considers the convicts as elements outside of society. We used the following psychodiagnostics methods to identify the psychological characteristics of the subject's personality. 


\subsection{Method 1. Personal questionnaire EPI (G. Aizenck)}

The purpose: diagnostics of extraversion, introversion, and neuroticism.

The procedure of the study was the group testing using the special blanks.

The nature of the opinions presented in the questionnaire regarding certain behaviors allows us to conclude about the level of formation of extraversion, introversion and neuroticism.

The individual results of the method are in the table 1.

Table 1. Levels of the development of scales of individual-psychological properties.

\begin{tabular}{|c|c|c|c|c|c|c|c|c|c|c|}
\hline \multirow[b]{2}{*}{ № } & \multirow[b]{2}{*}{ 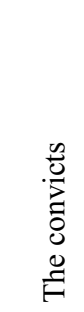 } & \multicolumn{9}{|c|}{ Levels of the development of scales of individual-psychological properties } \\
\hline & & 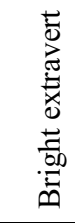 & 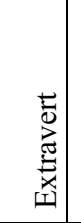 & 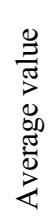 & 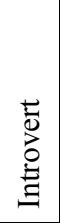 & 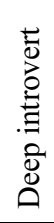 & 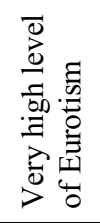 & 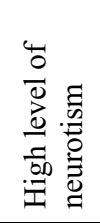 & 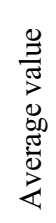 & 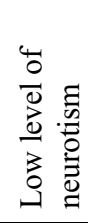 \\
\hline 1. & N.Z. & 21 & & & & & & & & 4 \\
\hline 2. & O.B & 24 & & & & & & 17 & & \\
\hline 3. & N.Zh. & & 17 & & & & 20 & & & \\
\hline 4 & E.S. & 25 & & & & & 22 & & & \\
\hline 5 & I.P. & & 16 & & & & & & & 5 \\
\hline 6 & K.L. & & 15 & & & & & 19 & & \\
\hline 7 & V.N. & 25 & & & & & 23 & & & \\
\hline
\end{tabular}

The results of the study say that we may have a conclusion that 4 convicts ( $57 \%$ ) are the bright extraverts, that's why they the act on the spur of the moment. They are impulsive quick-tempered, carefree, optimistic, prefer movement and action, tend to be aggressive, feelings and emotions do not have strict control. They are prone to risky actions, are characterized by increased excitability, unbalance, their actions are intermittent. ey are characterized by sharpness and impetuosity of movements, strength, impulsivity, vivid expression of emotional experiences, principled, irritability, intemperance, short temper, inability to self-control under emotional circumstances. Three convicts (43\%) - are extraverts. They are communicative, and they have a wide range of contacts, the necessity of the new contacts, and the desire of being in the spotlight. They choose the actions, not thinking. Two respondents have the low level of neurotism. It characterizes the strong reactions in relation to the stimuli that cause them. We can define them as people with a 
stable mentality, balanced, determined and calm. The average of the extraverts and introverts is not detected. There is no any introverts or deep introverts between them. Two convicts $(29 \%)$ have the high level of neurotism. We can characterize them as instable, unbalanced nervous processes, emotional instable, mild excitable and susceptible to mood changes persons. Three respondents have the very high level of neurotism. It is manifested in their irritability, intemperance, short temper, inability to self-control under emotional circumstances.

There is no any middle neurotism.

Summarizing the results, we can say that extroversion and neurotic demonstrations (the sphere of personality that influences the occurrence of negative factors of life and limits the ability of a person to solve them positively) of convicts is the reason of anger, aggression, and emotional instability.

\subsection{Method 2. Questionnaire of socio-psychological adaptation (K. Rogers, R. Diamond)}

The purpose: the identification of the degree of adaptability - maladaptability of the personality in the social sphere. The results are in the Table 2.

Table 2. The degree of adaptability - maladaptability in the social sphere.

\begin{tabular}{|c|c|c|c|c|c|c|c|c|c|c|c|c|c|c|}
\hline № & $\begin{array}{l}\stackrel{n}{0} \\
\stackrel{0}{2} \\
0 \\
0\end{array}$ & 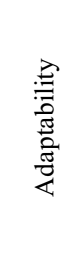 & 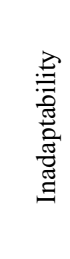 & 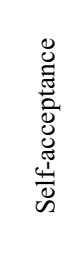 & 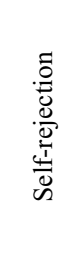 & 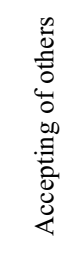 & 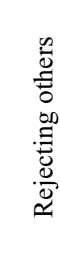 & 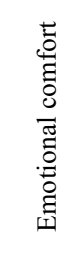 & 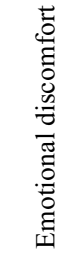 & 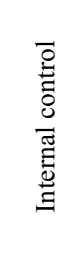 & 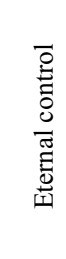 & 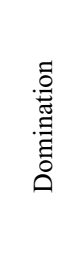 & 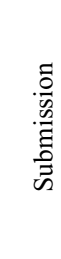 & 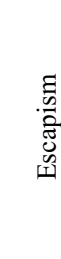 \\
\hline 1 & N.Z. & 69 & 97 & 24 & 17 & 12 & 24 & 15 & 26 & 26 & 30 & 12 & 19 & 18 \\
\hline 2 & O.B & 70 & 102 & 30 & 14 & 15 & 20 & 17 & 27 & 28 & 35 & 11 & 20 & 19 \\
\hline 3 & N.Zh. & 73 & 89 & 29 & 19 & 18 & 27 & 19 & 22 & 31 & 32 & 10 & 23 & 17 \\
\hline 4 & E.S. & 80 & 95 & 30 & 14 & 13 & 23 & 14 & 20 & 27 & 33 & 12 & 22 & 15 \\
\hline 5 & I.P. & 90 & 105 & 32 & 18 & 17 & 21 & 20 & 28 & 30 & 30 & 10 & 18 & 20 \\
\hline 6 & K.L. & 87 & 110 & 31 & 14 & 12 & 26 & 15 & 23 & 27 & 34 & 12 & 17 & 19 \\
\hline 7 & V.N. & 93 & 117 & 27 & 15 & 14 & 20 & 14 & 24 & 29 & 36 & 12 & 23 & 18 \\
\hline \multicolumn{2}{|c|}{ Average } & 80 & 102 & 29 & 16 & 14 & 23 & 16 & 24 & 28 & 33 & 11 & 20 & 18 \\
\hline
\end{tabular}

The results of the study say that we have identified maladjustment of the respondents. As a basis, we can give the data about the low level of self-acceptance and the low level of acceptance of the others. It means the contrasting yourself with others, emotional discomfort, a high level of externality, the desire for dominance, avoiding problems. The convicts do not see their own defects; they approve their behavior in general. Therefore, we can say about the positive self-esteem between them. They treat people around them critically, with a degree of contempt, expecting a negative attitude towards themselves. The high points of emotional discomfort - the essence of the negative emotional conditions says about it. On the scale of internality-externality, we can state that the respondents consider the thing that 
happened to them is the result of the action of external forces. They were led under the pressure of chance or other people. The high level of domination says about the tendency of convicts to suppress another person, to feel superior to others. The criteria of maladaptation are dominated in the convicts' responses. It means that they do not accept themselves and the others; it determines the presence of barriers in understanding their relevant experience, avoiding the solution of the problems, inflexibility. The high level of maladaptation says about immaturity of the individual, neurotic deviations, disharmony in the sphere of decisionmaking, which is the result of constant unsuccessful attempts of the individual to realize the goal or the presence of two or more equivalent goals.

\subsection{Method 3. "Strategy of behavior in a conflict situation" (K. Thomas)}

The purpose: the study of the individual predisposition of a person to conflict interaction and the definition of conflict resolution styles. The results are in the table 3.

Table 3. The strategies of behavior in a conflict situation.

\begin{tabular}{|c|c|c|c|c|c|c|}
\hline № & Convicts & Opposition & Collaboration & Compromise & Avoidance & Adaption \\
\hline 1 & N.Z. & 10 & 3 & 0 & 4 & 0 \\
\hline 2 & O.B. & 11 & 5 & 2 & 6 & 0 \\
\hline 3 & N.Zh. & 12 & 0 & 0 & 8 & 3 \\
\hline 4 & E.S. & 12 & 0 & 0 & 5 & 7 \\
\hline 5 & I.P. & 11 & 2 & 5 & 0 & 0 \\
\hline 6 & K.L. & 12 & 0 & 0 & 0 & 6 \\
\hline 7 & V.N. & 10 & 4 & 3 & 0 & 0 \\
\hline
\end{tabular}

The results of the study say that all of the respondents, 7 persons $(100 \%)$, demonstrated the desire for confrontation. We may say that they prefer to go their own way and are capable of strong-willed decisions, assertiveness and selfishness. First, such people seek to satisfy their own interests at the expense of the interests of others and often use this strategy in cases when they feel that there is no other choice and that there is nothing to lose. We can say that the convicts belong to the category of rationalists. They don't carry about the others' opinion and they prove that they have their own problem solution, anyway. The next interpretation of the results of this method let us to determinate that the preference for behavioral styles was distributed as follows: Four respondents (57\%) want to defend their interests, but only if it is profitable for them, they cooperate. They are ready to spend some time searching for interests to develop a way to satisfy their true desire. The solution is important for the respondents, no one of them wants to remove himself and they find the alternatives. Three of the convicts $(43 \%)$ flatly do not accept such a strategy, because they do not want to look for new alternatives or find the acceptable compromises. In addition, three convicts compromise $(43 \%)$, but they will trade to find a way to influence the situation or change it. The convicts will give up a little in their interests in order to take advantage of the short-term benefit because of a suitable compromise that suits them. The compromise is often a successful retreat or the last opportunity to find the solution in this occasion. As a result, they will be able to achieve their goal by cunning, but it is unlikely that such a model solves the conflict completely. Four convicts (57\%) do not want to sacrifice their interests because of the wishes of others. They are sure that they have enough power for getting what they want. Analyzing 
the different approaches to the conflict, we have identified that four $(57 \%)$ of the seven respondents preferred the avoidance strategy. They avoid the problem; ignore it, seeking a postponement of the decision or using other techniques. It is likely, that these convicts use the strategy to have more time and get the additional information or to find somebody's support. Three respondents (43\%) deny this strategy, because they are confident in their own ability to defend the position. Three respondents (43\%) can adapt because they understand that winning in the conflict is impossible now. The have the strategy if it is necessary to mitigate the situation somewhat, and then return to this issue and defend their position. They also use this strategy, if the outcome of the case is not profitable for them. Four convicts $(57 \%)$ do not consider this strategy essential for themselves. In their opinion, such behavior characterizes only weak people, who know that the truth is not on their side. It is really important for them to protect their interests, more then to solve the good relationships with somebody.

\section{Discussion}

The dynamical structures of the personality orientation revealed with the help of the psychodiagnostic complex allowed us to identify three main types of convicts (with positive, negative and indefinite orientation). They have specific features in the nature of the manifestation of the substructure of beliefs, attitudes and life plans. These results became the basis for the development of the social integration of the convicts' program. The program of the social integration "The new day" aimed at the perception and understanding the identification of themselves, their life difficulties and problems, formation of a belief in the possibility of realizing oneself in the future. The aim of the program is to form and develop the emotional resilience, to decline the level of aggression, to identify the mistakes, to form the positive aims for the future.

The program tasks:

- to form a positive image of ego in convicts;

- to teach the convicts emotional stability, by actualizing the strengths of their personality;

- teach the skills of managing their emotions, actions, and be responsible for their own behavior and actions.

The work forms for the convicts; group trainings. It creates the conditions for forming the adequate emotional reaction on the impact, rethinking of the personal problems. Training techniques are aimed at the normalization of the psychoemotional state and the harmonious development of the convict's personality. The program consists of 12 training sessions, lasting 50-60 minutes; the frequency of meetings is one time per week. The content of the program provides for individual correction of participants, especially realizing the deep features of the personality. The use of different methods of the psychocorrection in the rehabilitation program is the most suitable variant that let us to solve the problems on the different levels of functioning the convict's mentality.

\section{Conclusions}

It is necessary to manage the pedagogical, social and psychological work with convicts in order to improve the process of social integration and increase its effectiveness. The use of the psychoeducational forms and method of work with convicts helps to increase the productivity of this process. The period of primary adaptation lasts for the first 2-3 months. We can characterize it by a strong tense mental state of the convicted person (a sense of hopelessness, doom, which become a negative factor in the self-consciousness of the individual). The cause of manifestation of stress is being in prison. It is associated with 
adaptation sentenced to the penitentiary institution. The social deprivation, changing the usual way of life are the consequences of it. The penitentiary stress negatively affects on the person's health, but it process the other destructive actions (conflicts, suicide, unlawful actions). That is why it is very important to facilitate the process of adaptation of first-time convicts to life in isolation and to outline the ways for their subsequent social integration. The courses of psychological training, juridical lessons, additional programs of social integration with the participation of representatives of public organizations and religious associations help in the formation of socially significant personal qualities, focused on generally accepted values, positive relationships with others and help the convicts to be ready for the social integration after the liberation. The system of external conditions indirectly stimulates the activity of the research subject, but it is necessary to take into account the fact that the choice of the subject's behavior is influenced by the elements of the situation.

\section{References}

1. Yu.A. Voronin, Reckless crime: current trends and problems of prevention, Bulletin of the South Ural State University. Series Right 1, 19 (2019) DOI: https://doi.org/10.14529/law190102

2. E.Z. Giniyatullina, Student crime as a threat to the criminological security of the system of general and secondary vocational education: state and dynamics, National security / nota bene 3, 407-416 (2015) DOI: https://doi.org/10.7256/2073-8560.2015.3.15386

3. D.I. Erezhipaliev, Juvenile delinquency at the present stage of development of Russian society, All-Russian Journal of Criminology 11, 1, 98-108 (2017) DOI: https://doi.org/10.17150/2500-4255.2017.11(1).98-108

4. A.A. Zajnetdinova, A.A. Rezyapov, The concept of modern juvenile delinquency, Colloquium-journal. Jurisprudence 3 (27), 37-39 (2019) DOI: https://doi.org/10.24411/2520-6990-2019-10020

5. N.M. Romanova, Group crime in adolescents in modern socio-psychological studies, Izvestiya Saratov university bulletin, Ser. Philosophy. Psychology. Pedagogy 16, 4, 443449 (2016) DOI: https://doi.org/10.18500/1819-7671-2016-16-4-443-449

6. J. Braithwaite, Crime as a cascade phenomenon, International Journal of Comparative and Applied Criminal Justice 44, 3 (2020) DOI: https://doi.org/10.1080/01924036.2019.1675180

7. G. Drawve, J.T. Walker, M. Felson, Juvenile offenders: an examination of distance-tocrime and crime clusters, Cartography and Geographic Information Science 42, 2 (2015) DOI: https://doi.org/10.1080/15230406.2014.963677

8. M.J.J. Kunst, B.W.C. Zwirs, Posttraumatic stress disorder symptom severity and fear of personal crime: exploring their interrelationship as a function of risk estimation, Psychology, Crime \& Law 20, 9 (2014) DOI: https://doi.org/10.1080/1068316X.2014.888430

9. Y. Loader, R. Sparks, Ideologies and crime: political ideas and the dynamics of crime control, Global Crime 17, 3-4 (2016) DOI: https://doi.org/10.1080/17440572.2016.1169926

10. R. Surette, Performance Crime and Justice, Current Issues in Criminal Justice 27, 2 (2015) DOI: https://doi.org/10.1080/10345329.2015.12036041

11. K.N. Kalashnikov, Crime in modern Russia: problems of territorial assessments and their interpretation, Issues of territorial development 3 (48) (2019) DOI: https://doi.org/10.15838/tdi.2019.3.48.4 
12. R. Adelman, R.L. Williams, G. Markle, S. Weiss, J. Charles, Urban crime rates and the changing face of immigration: Evidence across four decades, Global Crime 9, 1-2 (2008) DOI: https://doi.org/10.1080/17440570701862819

13. T.R. Kochel, Robustness of collective efficacy on crime in a developing nation: association with crime reduction compared to police services, Journal of Crime and Justice 36, 3 (2013) DOI: https://doi.org/10.1080/0735648X.2012.698102

14. L. Maria, D. Canter, D. Youngs, J. Synnott, Offenders' Crime Narratives Across Different Types of Crimes, Journal of Forensic Psychology Practice 15, 5 (2015) DOI: https://doi.org/10.1080/15228932.2015.1065620

15. I.A. Ahmetshina, Deviant behavior of children and adolescents: a textbook (M.: Publishing house " Ekon-Inform», 2018)

16. N.V. Olhovik, Recidivism among those sentenced to restriction of liberty, Bulletin of Tomsk State University 395, 151-154 (2015) DOI: https://doi.org/10.17223/15617793/395/25

17. O.A. Ryzhova, Features of the occurrence of imperfect and preventive measures in modern conditions, Electronic scientific journal "Science. Society. The state" 8, 2 (30) (2020) DOI: https://doi.org/10.21685/2307-9525-2020-8-2-15

18. H. Hofer, Crime and reactions to crime in 34 Swedish birth cohorts: from historical descriptions to forecasting the future, Journal of Scandinavian Studies in Criminology and Crime Prevention 15, 2 (2014) DOI: https://doi.org/10.1080/14043858.2014.918298 